\title{
Predicting skeletal stature using ancient DNA
}

\author{
2 Samantha L Cox ${ }^{1,2^{*}}$, Hannah Moots ${ }^{3}$, Jay T Stock ${ }^{4,5}$, Andrej Shbat ${ }^{6}$, Bárbara D Bitarello ${ }^{1}$, \\ 3 \\ 4 \\ 5 \\ 6 \\ 7 \\ 8 \\ 9 \\ 10 \\ 11 \\ 12 \\ 13 \\ ${ }^{1}$ Department of Genetics, Perelman School of Medicine, University of Pennsylvania, Philadelphia, PA \\ ${ }^{2}$ Physical Anthropology Section, Penn Museum, University of Pennsylvania, Philadelphia, PA \\ ${ }^{3}$ Department of Anthropology, Stanford University, Stanford, CA \\ ${ }^{4}$ Department of Anthropology, Western University, London, Ontario, Canada \\ ${ }^{5}$ Department of Archaeology, Max Planck Institute for the Science of Human History, Jena, Germany \\ ${ }^{6}$ Institute of Anatomy, First Faculty of Medicine, Charles University, Prague, Czech Republic \\ ${ }^{7}$ Department of Archaeogenetics, Max Planck Institute for the Science of Human History, Jena, Germany \\ ${ }^{8}$ Einstein Center Chronoi, Freie Universität Berlin, Berlin, Germany \\ ${ }^{9}$ Center for Functional Anatomy and Evolution, Johns Hopkins University School of Medicine, Baltimore, MD \\ *Correspondence to SLC (coxsl@sas.upenn.edu) or IM (mathi@pennmedicine.upenn.edu)
}

\begin{abstract}
Objectives Ancient DNA provides an opportunity to separate the genetic and environmental bases of complex traits by allowing direct estimation of genetic values in ancient individuals. Here, we test whether genetic scores for height in ancient individuals are predictive of their actual height, as inferred from skeletal remains. We estimate the contributions of genetic and environmental variables to observed phenotypic variation as a first step towards quantifying individual sources of morphological variation.

Materials and Methods We collected stature estimates and femur lengths from West Eurasian skeletal remains with published genome-wide ancient DNA data ( $\mathrm{n}=167$, dating from 33,000-850 BP). We also recorded genetic sex, genetic ancestry, date and paleoclimate data for each individual, and $\delta^{13} \mathrm{C}$ and $\delta^{15} \mathrm{~N}$ stable isotope values where available $(\mathrm{n}=67)$.

Results A polygenic score (PRS) for height predicts $6.8 \%$ of the variance in femur length in our data $(\mathrm{n}=117, \mathrm{SD}=0.0068 \%, \mathrm{p}<0.001)$, controlling for sex, ancestry, and date. This is consistent with the predictive power of height PRS in present-day populations and the low coverage of ancient samples. Comparatively, sex explains about $15 \%$ of the variance in femur length in our sample. Environmental effects also likely play a role in variation, independent of genetics, though with considerable uncertainty (longitude: $R^{2}=0.0317, \mathrm{SD}=0.009, \mathrm{p}=0.019$ ).

Discussion Polygenic scores explain a small but significant proportion of the variance in height in ancient individuals, though not enough to make useful predictions of individual phenotypes. However, environmental variables also contribute to phenotypic outcomes and understanding their interaction with direct genetic predictions will provide a framework with which to model how plasticity and genetic changes ultimately combine to drive adaptation and evolution.
\end{abstract}




\section{Introduction}

37 One of the central goals of biological anthropology is to understand the environmental and genetic contributions to phenotypic change. Skeletal series covering long time periods and diverse environments are informative, but limited by inability to separate these contributions - a limitation that can now be addressed with ancient DNA. The ability to generate genetic data from skeletal remains has had an enormous impact on studies of human history. By identifying genetic links among individuals and populations, ancient DNA allows us to reconstruct demographic histories on both large and small scales (Skoglund \& Mathieson, 2018; Racimo et al., 2020), as well as the effects of natural selection (Marciniak \& Perry, 2017). To learn about complex trait evolution, ancient DNA can be combined with information from genome-wide association studies (GWAS). These studies, now involving millions of individuals, have identified large numbers of single-nucleotide polymorphisms (SNPs) associated with hundreds of phenotypes (Visscher et al., 2017). Though the effect of any individual variant is typically small, the effects of many SNPs can be summed to produce a polygenic score (PRS) which can be thought of as an estimate of an individual's genetic potential or risk for a particular phenotype (Torkamani et al., 2018).

Height is a polygenic trait which is highly heritable and easy to measure. GWAS have identified thousands of SNPs significantly associated with height (Yengo et al., 2018). Each one has only a tiny effect- $\pm 1-2 \mathrm{~mm}$ per SNP - but combined explain around $25 \%$ of the phentoypic variance in present-day populations of European ancestry (Yengo et al., 2018). Contingent upon reasonable preservation of skeletal remains, stature estimation from long bones is relatively straightforward, and there is an excellent record of changes in stature in many parts of the world (Bogin \& Keep, 1999; Cohen \& Crane-Kramer, 2007; Ruff, 2018; Rosenstock et al., 2019). On a population level, changes in polygenic score in Europe computed from ancient DNA largely track trends in stature in the European skeletal record (Cox et al., 2019). However, environmental effects on stature can still be large, as shown by $20^{\text {th }}$ century secular trends (NCD Risk Factor Collaboration, 2016), and are not confined to recent history. For example, during the Bronze Age, genetic predictions suggest increasing stature, but estimated skeletal heights actually decrease (Cox et al., 2019).

Polygenic scores have three main limitations. First, due to incomplete correction of population stratification in GWAS, they can capture environmental variation in present-day populations leading to ancestry-related biases (Sohail et al., 2019; Berg et al., 2019). Second, their accuracy decreases as genetic distance from the present-day European ancestry GWAS populations increases (Martin et al., 2019). Finally, their accuracy can be reduced by environmental differences, even within-population (Mostafavi et al., 2020). We therefore set out to test whether polygenic scores based on present-day GWAS predict height in ancient individuals by collecting data for individuals with both ancient DNA and skeletal measurements. This allows us to assess the validity of complex trait prediction in 71 ancient individuals, and whether we can use this approach to understand the relationship between 2 genetic and environmental components of stature and, perhaps, of other phenotypes. 
Table 1: Inverted stature estimation equations

\begin{tabular}{|c|c|c|c|c|}
\hline Reference & & Stature Equation & Error $(\mathrm{cm})$ & Femur Equation \\
\hline \multirow[t]{2}{*}{ Manouvrier $(1892)^{*}$} & Females & $49.319+2.543$ Femur & & $\frac{\text { Stature }-49.319}{2.543}$ \\
\hline & Males & $71.065+2.13$ Femur & & $\frac{\text { Stature }-71.065}{2.13}$ \\
\hline \multirow[t]{2}{*}{ Pearson (1899) } & Females & $72.844+1.945$ Femur & & $\frac{\text { Stature }-81.306}{1.88}$ \\
\hline & Males & $81.306+1.88$ Femur & & $\frac{\text { Stature }-81.306}{1.88}$ \\
\hline Breitinger (1937) & Males & $94.31+1.64$ Femur & \pm 4.8 & $\frac{\text { Stature }-94.31}{1.64}$ \\
\hline Bach (1965) & Females & $106.69+1.313$ Femur & \pm 4.1 & $\frac{\text { Stature }-106.69}{1.313}$ \\
\hline \multirow[t]{2}{*}{ Trotter \& Gleser (1952) } & White females & $54.10+2.47$ Femur & \pm 3.72 & $\frac{\text { Stature }-54.10}{2.47}$ \\
\hline & White males & $61.41+2.38$ Femur & \pm 3.27 & $\frac{\text { Stature-61.41 }}{2.38}$ \\
\hline Sjøvold (1990) & Independent & $49.96+2.63$ Femur & \pm 4.52 & $\frac{\text { Stature-49.96 }}{2.63}$ \\
\hline \multirow[t]{2}{*}{ Ruff et al. (2012) } & Females & $43.56+2.69$ Femur & \pm 2.92 & $\frac{\text { Stature }-43.56}{2.69}$ \\
\hline & Males & $42.85+2.72$ Fermur & \pm 3.21 & $\frac{\text { Stature }-42.85}{2.72}$ \\
\hline
\end{tabular}

${ }^{*}$ These equations are interpolated from the data given in the tables of the original publication.

\section{Materials and Methods}

\section{Data Collection}

75 We collected genetic data from published ancient DNA (aDNA) studies (31,000-850BP). Most in-

76 dividuals had pseudo-haploid genotypes at a set of 1.24 million SNPs (the "1240k array") and for

77 individuals with shotgun sequence data we randomly selected a single read at each of the covered

78 sites. The majority of the available ancient DNA data comes from Western Eurasia and so we

79 focused on this region, broadly defined (including individuals from up to $100^{\circ} \mathrm{E}$ longitude).

80 For each individual with published aDNA, we attempted to find data on their skeletal measure-

81 ments. Some aDNA papers include stature and/or femur length measurements in their supplemental

82 materials. For other individuals, we searched archaeological and anthropological literature for pub-

83 lished data. However, the vast majority of published aDNA data come from skeletal individuals

84 which are either unpublished or highly fragmented and therefore unmeasurable. We also report new 85 measurements for 30 individuals (Supplementary Table 1).

86 For each individual, we recorded maximum femur length, when available, otherwise we recorded

87 the estimated stature and estimation method. For individuals with published femur lengths, we es-

88 timated stature using the method of Ruff et al. (2012). We restricted analyses to adult individuals

89 free from reported major pathology. Ultimately, from approximately 4000 published aDNA samples

90 (Martiniano et al., 2016; Mittnik et al., 2019; Mathieson et al., 2018; Olalde et al., 2019; de Bar- 

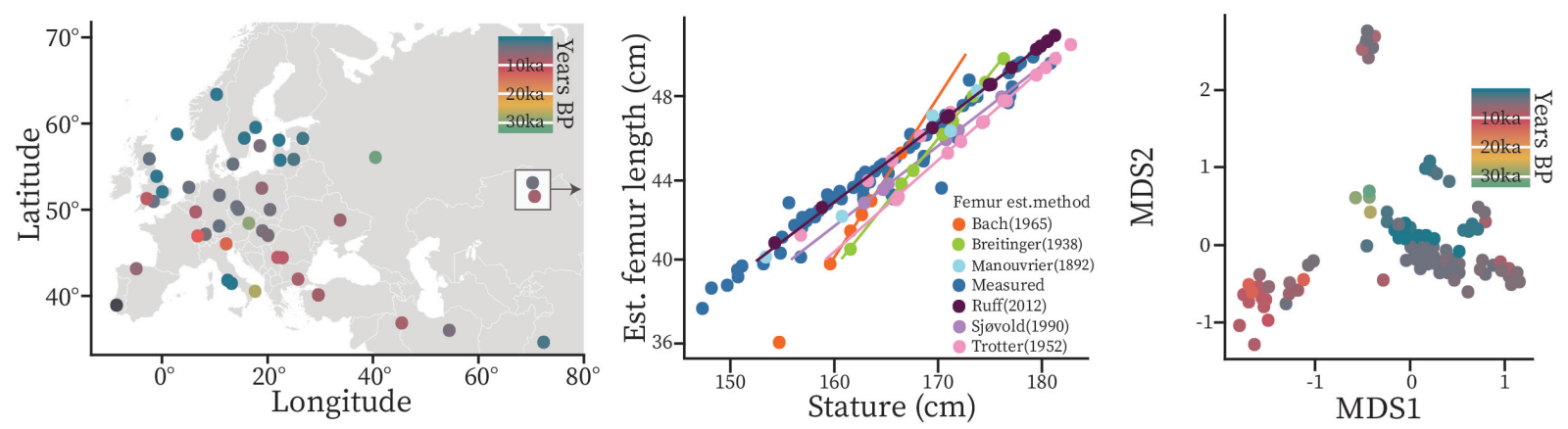

Figure 1: A) map of sites with specimens with both ancient DNA and metric data; B) The relationship between skeletal statures and femur length. Lines indicate the regression line for each stature estimation method. The stature for the outlying individual in the lower left was estimated using the Bach (1965) method, and was removed from further analysis. For all individuals with directly measured femora, stature was estimated using the method by Ruff et al. (2012); C) The first two MDS axes of the genetic data summarizing the genetic ancestry of the samples. Clusters correlate with time, and are largely associated with substantial shifts in genetic ancestry. The cluster in the top right corner represents the most eastern individuals in our sample, from present-day Siberia.

91 ros Damgaard et al., 2018; Mittnik et al., 2018; Fu et al., 2016; Schiffels et al., 2016; Narasimhan 92 et al., 2019; Lipson et al., 2017; Olalde et al., 2018; Brace et al., 2019; González-Fortes et al., 2017; 93 Furtwängler et al., 2020; Fernandes et al., 2018; Antonio et al., 2019; Sikora et al., 2017; Krzewińska et al., 2018; Margaryan et al., 2020; Mathieson et al., 2015; Schroeder et al., 2019), we compiled metric data for 167 individuals (Caffell \& Holst, 2012; Tebelškis \& Jankauskas, 2002; AlpaslanRoodenberg, 2001; Dunwell, 2007; Andrews \& Thompson, 2016; Köhler et al., 2017; Fokkens et al., 2017; Boroneant, 2010; Pardini, 1977; Frei et al., 2019; Kjellström, 2005; Cairns, 2015; Price et al., 2016; Szczepanek, 2013; Alciati, 1967; Massy, 2018; Malmström et al., 2019; Berthold et al., 2008; Kitti, 2008; Saag et al., 2020; Auerbach \& Ruff, 2004; Auerbach, 2004; Schiffels et al., 2016; Rosenstock et al., 2019). We removed 28 samples with more than $95 \%$ missing genetic data and one individual with an unusually short femur (Fig. 1B), bringing the sample size to 138. Finally, 21

102

103

104

105

106

107

108

109

110

111 stature estimates used unknown methods and we removed them from the majority of tests, bringing the final sample size for most analyses to 117 (Supplementary Table 1).

There are a number of methods available for estimating living statures based on skeletal measurements. Population-specific methods are the most accurate, but are not available for every population (Ruff et al., 2012). Researchers ideally choose a method which has been developed on a population similar to that under investigation in terms of ancestry or body proportions; however, this is often not possible and there are a few methods which are most frequently used, even if not population-specific (e.g Trotter \& Gleser, 1952; Sjøvold, 1990; Ruff et al., 2012). Ideally we would compare statures estimated using the same equations but that was not possible since in many cases underlying data were not available. 
112

113

114

115

116 accurate stature estimate is the femur (Trotter \& Gleser, 1952; Ruff et al., 2012; Ruff, 2018) we

117 tried predicting maximum femur length rather than stature. Femur lengths were only published

118 for 78 out of our 167 individuals. For the other individuals, since statures are estimated as linear

119 functions of long bone lengths, we inverted the estimation equations to retrieve femur measurements

120 corresponding to each individual stature (Table 1; for further discussion on this approach see Köpke

121 \& Baten (2005); Rosenstock et al. (2019)). For individuals for which stature had been estimated

122 using a non-femur long bone, this procedure gives us the femur length which would have produced

123 the originally estimated stature (Fig. 1B). We confirmed that estimation method did not have a

124 significant effect on femur lengths estimated using this approach $(\mathrm{P}=0.539)$. We used femur length

125 rather than estimated stature for most analyses, omitting $(\mathrm{n}=21)$ individuals for which the stature

126 estimation method was not cited. Finally, the slope of the regression line from which the Bach (1965)

127 formula is derived deviates from those of the other estimation methods and produces outlier femur

128 measurements (Fig. 1B). The applicability of the Bach (1965) method has also been questioned by

129 other researchers (Sládek et al., 2015). This method was only used for a few individuals ( $\mathrm{n}=3$ ), and

130 as inclusion of these individuals did not affect prediction results, all were included in the analysis

131 except for one. This individual (DNA sample ID: AITI_95, a genetic female from the Bronze Age

132 German site of Kleinaitingen-Gewerbegebiet Nord) was estimated to have had an unusually short

133 femur (approx $36 \mathrm{~cm}$, estimated stature $=154 \mathrm{~cm}$ ) and was excluded as we could not be confident

$\mathbf{1 3 4}$ in the accuracy of the estimate.

135 We also collected other variables for inclusion in our models: ancestry, date, sex, climate, and

136 diet. We estimated genetic ancestry by multi-dimensional scaling (MDS, with $\mathrm{k}=4$ dimensions) of

137 the genetic data - referred to collectively as the "ancestry" variable. We determined the date of each

138 sample based on the calibrated radiocarbon dates reported in the original publication of the genetic

139 data. For the few samples for which there was no direct date available, we used the mid-point of the

140 archaeological date range. Genetic sex was reported in the original publications. Climate variables of

141 mean daily temperature and annual precipitation were obtained from the $5 \mathrm{~min}$ (medium resolution,

142 data points every $10 \mathrm{~km}$ ) paleoclimate dataset available at PaleoClim.org (Brown et al., 2018). We

143 extracted the relevant data using the raster package (Hijmans \& van Etten, 2012) in R. Using

144 geographic coordinates, we calculated the distance from the sites where skeletons were excavated

145 to the surrounding climate data points (using the gdist() function from the Imap package; Wallace

146 (2012)), and chose the point closest to the site to represent its climate. For Western Europe, most

147 sites are within a few kilometers of available climate data; however, there are a handful of sites

148 in present-day Russia and the Middle East which are quite far from any available PaleoClim data

$149(200-1500 \mathrm{~km})$. To represent diet, we searched for stable isotope data $\left(\delta^{13} C\right.$ and $\left.\delta^{15} N\right)$. However, 

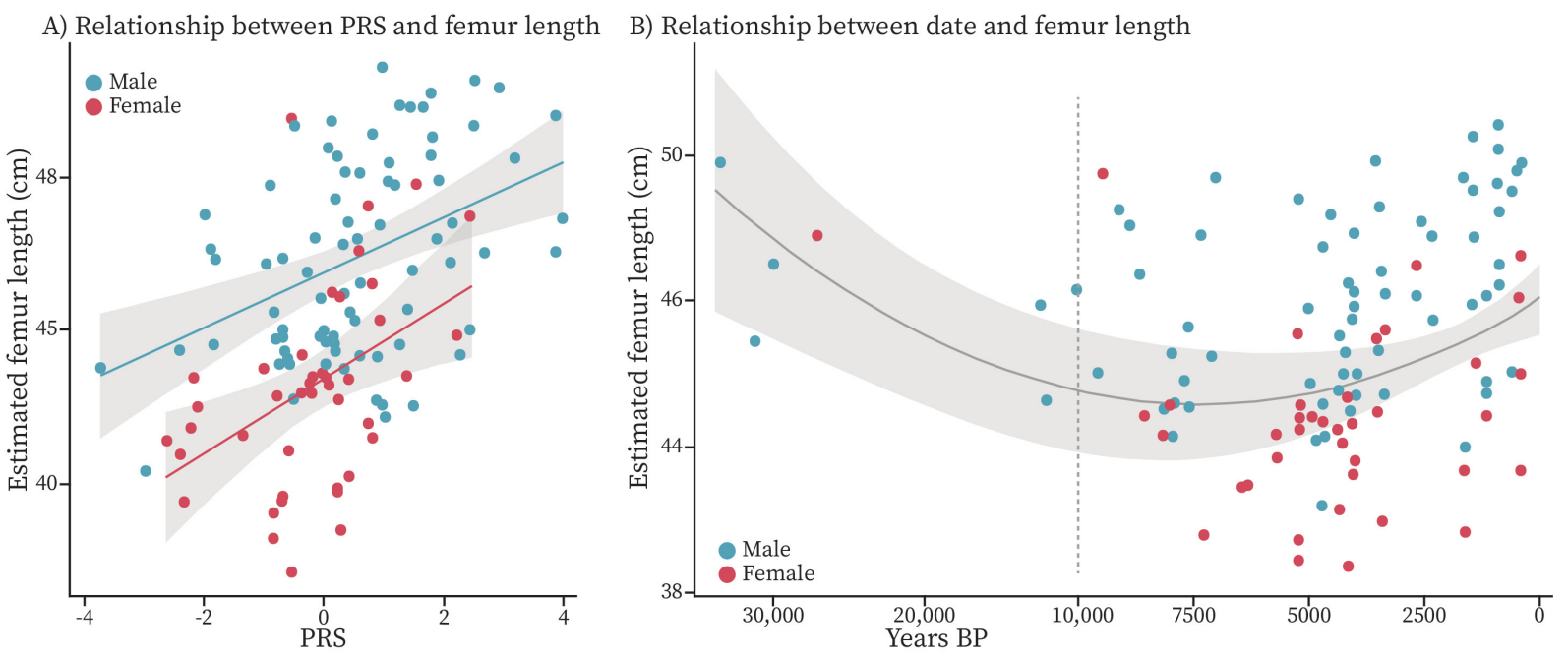

Figure 2: A) Plot of the linear relationship between PRS and femur length. Higher PRS values are associated with longer femur lengths in the data. Colors indicate sex, the lines are the regression lines for males and females separately, and the grey shadows are the $95 \%$ confidence intervals. For our main results, we assume the slope of this regression is identical between sexes. B) Plot of the fitted quadratic relationship between date and femur length. Colors indicate sex, the solid grey line is the quadratic fit line for the pooled-sex group, the grey shadow is the $95 \%$ confidence interval, and the vertical dashed line indicates the change in x-axis plotting scale.

150 these data were only published for about half the individuals ( $\mathrm{n}=66$ )(Price et al., 2016; Antanaitis-

151 Jacobs et al., 2009; Stockhammer et al., 2015; Scheibner, 2016; Antanaitis-Jacobs \& Ogrinc, 2000;

152 Lehuray et al., 2006; Afshar et al., 2019; Waterman et al., 2016; Weber et al., 2011, 2016; Müldner

153 et al., 2011; Antonio et al., 2019; Szczepanek, 2013; Olalde et al., 2018; Andrews \& Thompson, 2016;

154 Dunwell, 2007; Mathieson et al., 2018; Berthold et al., 2008; Malmström et al., 2019; Kjellström,

155 2005; Kjellström et al., 2009; Scheibner, 2016).

\section{Polygenic Scores}

157 We calculated PRS using UK Biobank standing height summary statistics calculated by the Neale Lab

158 (2018). After intersecting these sites with those on the 1240k array, we tested a variety of PRS 159 constructions. For the main analysis, we further restricted to HapMap3 SNPs (leaving 405,502 re160 maining) and estimated SNP weights using the infinitesimal model of LDpred (Vilhjalmsson et al., $1612015)$ with an LD reference panel made up of 8,000 randomly chosen individuals of British ancestry

162 from the UK Biobank. We then computed polygenic scores using the --score command in plink 163 (Chang et al., 2015). As an alternative approach, we also calculated PRS using a simpler clump$164 \mathrm{ing} /$ thresholding approach. Clumping parameters included all combinations of: $10^{-2}, 10^{-6}$, and $16510^{-8}$ p-value cut-offs; 100, 250, and $500 \mathrm{~kb}$ windows; and $r^{2}$ cutoffs of $0.1,0.3$, and 0.5 . We used 166 plink 1.9 (Chang et al., 2015) to clump (--clump) SNPs using these parameters with an LD reference 
167 panel made up of 500 individuals from five European populations (1000 Genomes Project Consor-

168 tium, 2015), and to compute polygenic scores (--score). In both approaches, missing genotypes are

169 replaced by the sample mean frequency - a conservative approach that shrinks scores towards the

170 sample mean.

\section{Genotype Imputation}

172 The genetic data are relatively low coverage (haploid median $=0.607$, range $=0.001-1$ ). Therefore it 173 is not possible to infer diploid genotypes, and we use pseudo-haploid data that represents a single

174 allele at each site. This limits performance of the PRS because effectively we only see at most half of 175 each individual's genotype. In practice samples often perform worse because many sites are missing 176 data entirely. We attempted to improve individual prediction by using genotype imputation to infer 177 diploid genotypes and missing sites. We downloaded bam files for each of the individuals in our 178 sample, and extracted reference/alternative read counts at each of the $1240 \mathrm{k}$ sites. We computed 179 genotype likelihoods based on a binomial distribution of reads with a $2 \%$ rate of error. We then ran 180 Beagle4 (Browning \& Browning, 2016) using a reference panel made up of the European ancestry 181 populations from the 1000 Genomes Project Consortium (2015) to impute diploid genotypes at all 182 1240k sites, including those that were missing in the original data. Finally, we set any sites with a 183 genotype imputation accuracy $R^{2}<0.8$ to missing.

\section{Statistical Analysis}

185 We fit linear models of femur length (and stature) as a function of sex, PRS, genome-wide ancestry, 186 and date, and also included stable isotope and climate variables when appropriate. The ancestry 187 component includes 4 MDS axes. Date includes both date (years before present) and date squared, 188 to allow for nonlinear effects (Fig. 2B). We evaluated the contribution of each term based on the 189 difference in $R^{2}$ between the full model and a reduced model without the term being tested; we 190 refer to this difference simply as $R^{2}$. To test the significance of a particular variable, we permuted 191 its value within the dataset, keeping constant those variables which were not being tested. We 192 permuted each test variable 10,000 times. We computed P-values as the proportion of times that 193 the $R^{2}$ value in the original data was greater than the $R^{2}$ of the permuted distribution. When 194 permuting terms with multiple components, for example ancestry, we ensured that the relationship 195 between each of the permuted components was maintained.

\section{Results}

197 The LDpred polygenic score predicts $6.8 \%$ of the variation in femur length in our data. We fitted 198 linear models including sex, PRS (Fig. 2A), ancestry (4 MDS components) and date (including 199 date squared; Fig. 2B) and evaluated significance by permuting the terms being tested. The $R^{2}$ of 200 PRS was $0.068(\mathrm{SD}=0.007, \mathrm{p}=0.000)$ (Table 2$)$, showing that it explains a small but statistically 
Table 2: Linear model results

\begin{tabular}{llc|lc}
\hline \hline & & & \multicolumn{2}{|c}{ permuted values } \\
Model & Variables & $R^{2}$ & $R^{2} \mathrm{SD}$ & p-value \\
\hline $\begin{array}{l}\text { femur length } \\
(\mathrm{cm}) \text { with }\end{array}$ & PRS & 0.068 & 0.0068 & 0.000 \\
$\begin{array}{l}\text { ancestry } \\
(\mathrm{n}=117)\end{array}$ & sex & 0.056 & 0.0131 & 0.015 \\
\hline femur length, no & PRS & 0.151 & 0.0081 & 0.000 \\
ancestry & sex & 0.043 & 0.0090 & 0.009 \\
$(\mathrm{n}=117)$ & date & 0.088 & 0.0074 & 0.000 \\
\hline stature $(\mathrm{n}=138)$ & PRS & 0.172 & 0.0089 & 0.000 \\
& ancestry & 0.036 & 0.0098 & 0.03 \\
& sex & 0.048 & $0 . .0049$ & 0.000 \\
& date & 0.055 & 0.0113 & 0.009 \\
& estimation method & 0.055 & 0.015 & 0.060 \\
\hline
\end{tabular}

201 significant proportion of the variance in femur length in our data, once the other variables are taken 202 into account. For comparison, this is less than half of the variance explained by $\operatorname{sex}\left(R^{2}=0.15\right)$.

203 Ancestry had $R^{2}=0.056$ ( $\left.\mathrm{SD}=0.0131, \mathrm{p}=0.015\right)$; a contribution that may also partially reflect genetic

204 effects. In a model without ancestry, the $R^{2}$ of the PRS term increases to 0.088 , reflecting systematic

205 variation in PRS with ancestry. Date has $R^{2}=0.043$ although this largely reflects differences between

206 the Early Upper Paleolithic and later populations (Fig. 2B). When we predicted stature, rather

207 than femur length, including a constant term for estimation method, we found consistent results,

208 though with a slightly lower $R^{2}$, possibly due to the error introduced by the variation in estimation

209 methods (PRS $R^{2}=0.048, \mathrm{SD}=0.0049, \mathrm{p}=0.000$ ) (Table 2).

210 Almost all the predictive power of the PRS comes from samples above median coverage (haploid

211 median coverage $=0.63$, Fig. $3 \mathrm{~B} \& \mathrm{C}$ ). To test how PRS construction might affect prediction results,

212 we also constructed PRS using a more traditional clumping and thresholding method. For this,

213 we computed PRS using p-value cut-offs of $10^{-2}, 10^{-6}$, and $10^{-8}, r^{2}$ of $0.1,0.3$, and 0.5 , with

214 100, 250, and 500kb windows. LDpred provides the highest predicted $R^{2}$ values, though there are

215 sets of clumping parameters which perform similarly. In Fig. 3A, we report the $R^{2}$ values for all 216 tested clumping parameter values. Attempting to improve prediction, we imputed diploid geno217 types, including missing SNPs, in our dataset (imputed diploid median coverage=0.987). Against 218 expectation, the imputed data generally decreased accuracy compared to the unimputed data for 
A) All samples

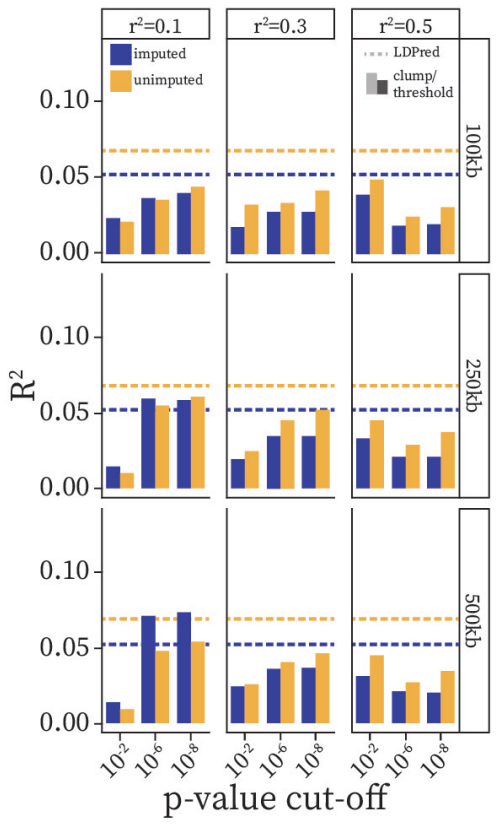

B) Above median coverage

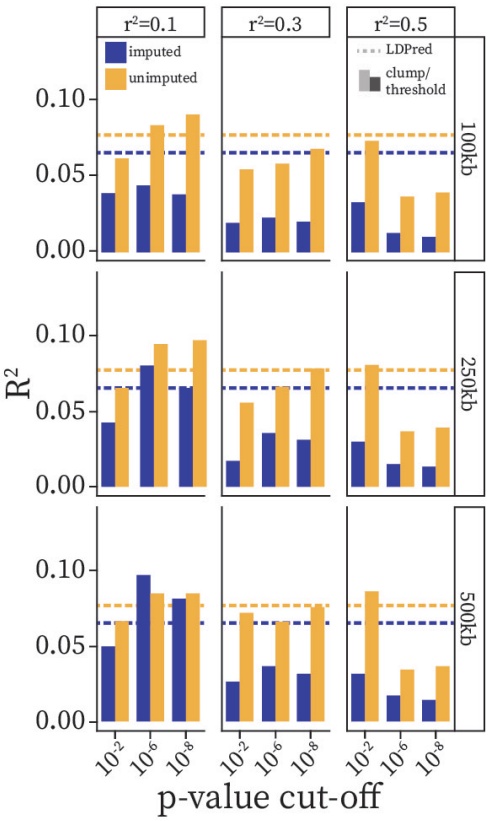

C) Below median coverage

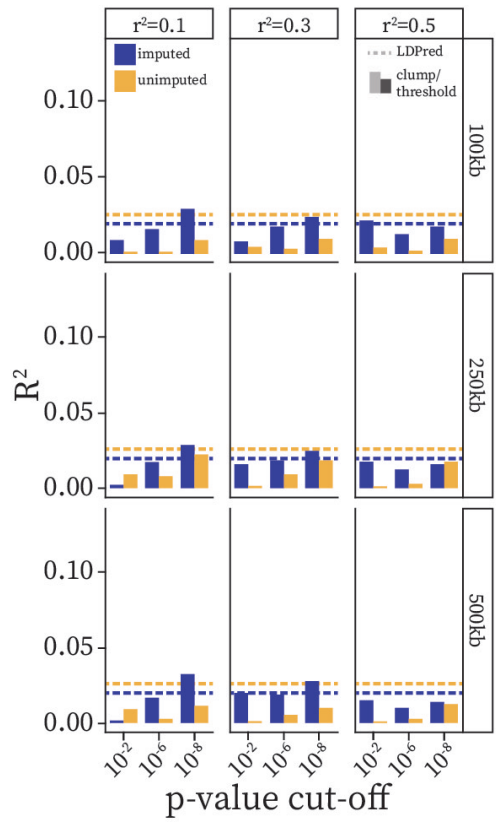

Figure 3: Bar plots showing the $R^{2}$ value for each set of clumping and thresholding parameter combinations (window size, $r^{2}, p$-value cut-off) used for PRS construction. Horizontal dashed lines show the $R^{2}$ values from the LDpred PRS. Regression models include sex, date, and ancestry as covariates.

219 higher coverage samples. For lower coverage samples imputation did improve $R^{2}$ for the clumping

220

221

222

223

224

225

226

227

228

229

230

231

232

233

234

approaches but not for $L D$ pred (Fig. 3). One possibility is that imputation biases genetic variation to be similar to samples in the reference panel, leading to no increase in predictive power. Supporting this, if we perform MDS on the imputed genotypes, the ancestry term is no longer significant $\left(R^{2}=0.006, \mathrm{P}=0.58\right)$, suggesting a loss of information.

When we include geographic and climate variables in the model, the contributions of annual precipitation, mean daily temperature and latitude, are non-significant (Table 3, all $<1 \%$ ). Longitude has an $R^{2}$ of $3 \%\left(\mathrm{P}=0.006\right.$; an increase of $\left.0.07 \mathrm{~cm} /{ }^{\circ}\right)$, but its contribution to the model changes depending on which other variables are included. For instance, when ancestry is excluded from the model, longitude is no longer significant $(\mathrm{p}=0.099)$, suggesting a complex relationship which may obscure its effects. It is likely that this variable is a proxy for others that are not included in our models, and so this significant value is difficult to interpret. Finally, the effects of stable isotope values are not significant (Table 3), though this might be due to the relatively small sample size $(\mathrm{n}=67)$. Indeed, neither PRS nor ancestry is significant in this subset. Though not significant, our results suggest that increasing $\delta^{15} \mathrm{~N}$ may be associated with increased femur length (increase of 0.4 $\left.\mathrm{cm} / \%_{00} \delta^{15} \mathrm{~N}\right)$. 
Table 3: Linear model results for femur length, climate and stable isotope variables

\begin{tabular}{lll|ll}
\hline \hline & & & \multicolumn{2}{|l}{ permuted values } \\
Model & Variables & $R^{2}$ & $R^{2} \mathrm{SD}$ & $\mathrm{p}$-value \\
\hline & PRS & 0.0569 & 0.0066 & 0.000 \\
Femur length & ancestry & 0.0679 & 0.0130 & 0.004 \\
with climate & sex & 0.1251 & 0.0079 & 0.000 \\
and & date & 0.0690 & 0.0093 & 0.000 \\
$\begin{array}{l}\text { geographic } \\
\text { variables }\end{array}$ & latitude & 0.0047 & 0.0083 & 0.381 \\
(n=117) & longitude & 0.0317 & 0.0090 & 0.019 \\
& avgTemp & 0.0050 & 0.0065 & 0.296 \\
& annualPrecip & 0.0074 & 0.0058 & 0.191 \\
\hline $\begin{array}{l}\text { Femur length } \\
\text { with diet }\end{array}$ & PRS & 0.002 & 0.0117 & 0.623 \\
variables & ancestry & 0.054 & 0.0245 & 0.205 \\
$(\mathrm{n}=67)$ & sex & 0.234 & 0.0209 & 0.000 \\
& date & 0.032 & 0.0171 & 0.171 \\
& $\delta^{13} \mathrm{C}$ & 0.012 & 0.0125 & 0.266 \\
& $\delta^{15} \mathrm{~N}$ & 0.030 & 0.0147 & 0.098 \\
\hline
\end{tabular}




\section{Discussion and Conclusion}

236 We find that that we can predict a small but statistically significant proportion of individual height

237 variation using polygenic scores in ancient individuals. Given that our data are pseudo-haploid,

238 meaning we observed only one chromosome of each chromosome pair, we would automatically expect

239 our PRS predictions to perform half as well as they would on diploid data. From there, on average,

$\mathbf{2 4 0}$ about $50 \%$ of SNPS are missing in each individual, decreasing our expected predictions by another

241 half. Therefore, we would expect to be able to predict about one quarter of the variation that can

242 be predicted in present-day Europeans, which is roughly consistent with our findings. Surprisingly,

243 we find that genotype imputation, at least as implemented here, does not substantially increase

244 predictive accuracy. Further developments in imputation approaches specific to ancient DNA might

245 provide improvements in the future. Our results show that polygenic scores cannot accurately

246 predict individual traits, but do support their application to the quantitative study of evolutionary

247 trends and environmental relationships on a population level (Cox et al., 2019).

248 There is a correlation between PRS and ancestry: genome-wide ancestry explains a similar

249 amount of variation in height as the PRS, but when ancestry is removed, the variation accounted

250 for by the PRS increases. There are two non-exclusive explanations for this observation. One is

251 that genetic height varies systematically with ancestry - consistent with the observation that, on a

252 population level, stature tracks genetically predicted height through time (Cox et al., 2019). A large

253 portion of the predicted genetic change in stature is attributable to major admixture events, which

254 may therefore make a substantial contribution to changes in stature over time. Differences in genetic

255 height among populations do not necessarily indicate directional selection - substantial differences

256 can also arise under neutrality or even stabilizing selection (Harpak \& Przeworski, 2020). A second

257 possible explanation is that ancestry is spuriously correlated with environmental variables from the

258 GWAS population. Known as population stratification, this is a common and potentially strong

259 source of bias in GWAS analysis, and while measures are taken to reduce its impact, there can

260 still be evidence of residual population stratification in the GWAS results (Sohail et al., 2019; Berg

261 et al., 2019). However, for this to affect our study it would also require a somewhat coincidental

262 correlation between ancient and present-day stratification. With current methods and data, the

263 signatures of residual structure and ancestry-linked variation would appear identical. However, even

264 if the contribution of genome-wide ancestry is entirely driven by stratification, the polygenic score

265 still explains a significant proportion of phenotypic variation beyond its interaction with ancestry.

266 In addition to the genetic component, dietary variables can have a substantial impact on height

267 outcomes. Nitrogen values are mainly associated with dietary protein intake from both plant and

268 animal sources, but are also correlated to factors such as climate (O'Brien, 2015; Scheibner, 2016),

269 and there is an established link between protein malnutrition/undernourishment and stunting of

270 linear growth in children (Ghosh, 2016). Given this, we would expect to see a positive trend

271 between nitrogen values and femur length which is present, though not significant, in our data. 
272 Carbon values are more indicative of dietary plant resources, and of the terrestrial vs. marine

273 vs. limnic provenance of food (O'Brien, 2015; Scheibner, 2016). $C^{4}$ plants, such as millet, lead to

274 significantly lowered $\delta^{13} \mathrm{C}$ values and became widespread in Western Eurasia after ca. 3000 BCE.

275 While Palaeolithic diets were mainly terrestrial, increased variance of $\delta^{13} \mathrm{C}$ values around 10,000

276 BCE reflect the increased exploitation of aquatic food resources (Scheibner, 2016). Hence, our

277 expectations for the effect of $\delta^{13} \mathrm{C}$ on height are unclear. Moreover, stable isotope values in general

278 may co-vary to some extent with both date and climate. Another issue is that, we did not control for

279 the bone element from which collagen samples originated. Samples might not necessarily reflect the

$\mathbf{2 8 0}$ diet of the individual during the period that is relevant for the establishment of stature. Thus, we

281 consider the interpretation of isotope values in our study as generally representative of subsistence

282 patterns, rather than quantitative assays of relevant diet.

283 Previous work found a relationship between latitude and height in Europe which we do not

284 observe in our sample. Cox et al. (2019) suggested that the observed latitudinal trend might

285 be genetically driven by post-Neolithic Steppe migrations; however, even if we remove the ancestry

286 term from our model, latitude is still not sigificant. However, our sample is biased towards Northern

287 European collections for which we found more published metrics on DNA sampled individuals. Lack

288 of a substantial Southern European sample might explain why we do not see a relationship.

289 Longitude has also previously been shown to correlate with stature in the European pre-Bronze

290 Age periods (Ruff, 2018; Cox et al., 2019), as have climate variables (Ruff, 2018). We do replicate

291 this observation. However, this is partly driven by the relatively tall individuals from the Danube

292 Gorges region of Southeastern Europe (12 individuals in our sample). It has been well documented

293 that the populations of this region do not follow the same height decreases that affect the rest of the

294 continent through history. This has often been interpreted as a genetic trait since the nutritional

295 status and general environment in recent times has been considered less than ideal (see citations in

296 Ruff \& Holt (2018) for further discussion). In our analysis, neither genetic ancestry nor polygenic

297 score predict this variation although there may be genetic factors that we do not capture. The trend

298 might also be driven by environmental factors, though we do not have the data here to speculate

299 about what factors might be involved. This motivates further study of the basis of the distinct

300 trends in this region.

301 It is not currently practical to use genetic (or environmental) data to predict individual pheno-

302 types for height or other complex traits. However, our study shows how polygenic scores can begin

303 to separate the effects of genetics and environment on a population level. We have shown that

304 genetic variation can independently predict stature, validating the use of polygenic scores to track

305 evolutionary changes (Cox et al., 2019). Future work should therefore focus on compiling anthro-

306 pometric, genetic, and environmental data, as our results show promise for the application of this

307 approach on more comprehensive data. With larger samples and more detailed information about

308 environmental covariates, more accurate quantification of the role of environment and therefore of

309 the relative importance of genetics and environment should be possible. 


\section{Data Availability}

311 All ancient DNA data used in this paper are publicly available, please see their respective citations

312 for the sources. All skeletal metrics and polygenic scores analyzed in this paper are provided in

313 Supplementary Table 1.

\section{Acknowledgments}

315 This research was supported by a Research Fellowship from the Alfred P. Sloan Foundation (FG316 2018-10647), a New Investigator Research Grant from the Charles E. Kaufman Foundation (KA2018317 98559) and NIGMS award number R35GM133708. Some isotope and skeletal data were collected 318 in collaboration with Alisa Scheibner and Julia Ebert, within the Emmy-Noether-Projekt "LiVES" 319 funded by German Research Foundation Grant RO4148/1 (PI Eva Rosenstock). The content is 320 solely the responsibility of the authors and does not necessarily represent the official views of the 321 National Institutes of Health or other funding sources. This research made use of the UK Biobank 322 Resource under Application 33923.

323

324 325

326 327 328 329 330

331 332

333 334

335 336

337 338 339 340

\section{References}

1000 Genomes Project Consortium (2015). A global reference for human genetic variation. Nature, $526(7571), 68-74$.

Afshar, Z., Millard, A., Roberts, C., \& Gröcke, D. (2019). The evolution of diet during the 5th to 2nd millennium BCE for the population buried at Tepe Hissar, north-eastern Central Iranian Plateau: The stable isotope evidence. Journal of Archaeological Science: Reports, 27, 101983.

Alciati, G. (1967). I resti ossei umani delle necropoli dello Swat, W. Pakistan, Volume 1. Reports and Memoirs, Vol VIII. Rome: ISIAO.

Alpaslan-Roodenberg, S. (2001). Newly found human remains from Manteşe in the Yenişehir plain: the season of 2000. Anatolica, 27, 1-14.

Andrews, P., \& Thompson, S. (2016). A Early Beaker funerary monument at Porton Down, Wiltshire. Wiltshire Archaeological \& Natural History Magazine, 109, 38-82.

Antanaitis-Jacobs, I., \& Ogrinc, N. (2000). Chemical analysis of bone: stable isotope evidence of the diet of Neolithic and Bronze Age people in Lithuania. Istorija, 45, 3-12.

Antanaitis-Jacobs, I., Richards, M., Daugnora, L., Jankauskas, R., \& Orginc, N. (2009). Diet in early Lithuanian prehistory and the new stable isotope evidence. Archaeologia Baltica, 12, 12-30.

Antonio, M. L., Gao, Z., Moots, H. M., Lucci, M., Candilio, F., Sawyer, S., et al. (2019). Ancient Rome: A genetic crossroads of Europe and the Mediterranean. Science, 366 (6466), 708-714. 
341 Auerbach, B. M. (2004). The Goldman Dataset. https://web.utk.edu/ auerbach/GOLD.htm.

342 Auerbach, B. M., \& Ruff, C. B. (2004). Human body mass estimation: a comparison of "morphome-

343 tric" and "mechanical" methods. American Journal of Physical Anthropology, 125 (4), 331-342.

344 Bach, H. (1965). Zur Berechnung der Köperhöhe aus den langen Gliedmaßenknocken weiblicher

345 Skelette. Anthro Anz, (pp. 12-21).

346 Berg, J. J., Harpak, A., Sinnott-Armstrong, N., Joergensen, A. M., Mostafavi, H., Field, Y., et al. 347 (2019). Reduced signal for polygenic adaptation of height in UK biobank. eLife, 8, e39725.

348 Berthold, B., Alt, K., Bramanti, B., Drings, S., Kranzbühler, J., Meyer, C., et al. (2008). Die

349 Totenhütte von Benzingerode. Archäologie und Anthropologie. Landesamt für Denkmalpflege und

350 Archäologie Sachsen-Anhalt, Landesmuseum für Vorgeschichte.

351 Bogin, B., \& Keep, R. (1999). Eight thousand years of economic and political history in Latin 352 America revealed by anthropometry. Annals of Human Biology, 26, 333-351.

353 Boroneant, A. (2010). Ostrovul Corbului - o discuţie asupra mormintelor mezolitice şi neolitice 354 timpurii. Buletinui Muzeului Judeţean Teleorman, Serie Arheologie, 2, 5-27.

355 Brace, S., Diekmann, Y., Booth, T. J., van Dorp, L., Faltyskova, Z., Rohland, N., et al. (2019). 356 Ancient genomes indicate population replacement in Early Neolithic Britain. Nature Ecology $\mathcal{G}_{3}$ $357 \quad$ Evolution, 3(5), 765-771.

358 Breitinger, E. (1937). Zur Berechnung der Köperhöhe aus den langen Gliedmaßenknocken. Anthro 359 Anz, (pp. 249-274).

360 Brown, J. L., Hill, D. J., Dolan, A. M., Carnaval, A. C., \& Haywood, A. M. (2018). PaleoClim, 361 high spatial resolution paleoclimate surfaces for global land areas. Scientific Data, 5(1), 180254.

362 Browning, B. L., \& Browning, S. R. (2016). Genotype Imputation with Millions of Reference 363 Samples. American Journal of Human Genetics, 98(1), 116-126.

364 Caffell, A., \& Holst, M. (2012). Osteological Analysis 3 and 6 Driffield Terrace, York, North 365 Yorkshire. Tech. Rep. 0212, York Osteoarchaeology Ltd.

366 Cairns, A. M. (2015). Health in Medieval and Early Modern Norway: A comparative analysis of 367 the impact of social, economic, and environmental change on skeletal remains. Ph.D. thesis, 368 Australian National University.

369 Chang, C., Chow, C., Tellier, L., Vattikuti, S., Purcell, S., \& Lee, J. (2015). Second-generation 370 PLINK: rising to the challenge of larger and richer datasets. GigaScience, 4.

371 Cohen, M. N., \& Crane-Kramer, G. M. M. (Eds.) (2007). Health: Skeletal Indicators of Agricultural 372 and Economic Intensification. Gainesville: University Press of Florida. 
Cox, S. L., Ruff, C. B., Maier, R. M., \& Mathieson, I. (2019). Genetic contributions to variation in human stature in prehistoric Europe. Proceedings of the National Academy of Sciences, 116(43), 21484-21492.

de Barros Damgaard, P., Martiniano, R., Kamm, J., Moreno-Mayar, J. V., Kroonen, G., Peyrot, M., et al. (2018). The first horse herders and the impact of early Bronze Age steppe expansions into Asia. Science, 360(6396).

Dunwell, A. (2007). Cist Burials and an Iron Age settlement at Dryburn Bridge, Innerwick, East Lothian. Scottish Archaeological Internet Report, 24.

Fernandes, D. M., Strapagiel, D., Borówka, P., Marciniak, B., Żądzińska, E., Sirak, K., et al. (2018). A genomic Neolithic time transect of hunter-farmer admixture in central Poland. Scientific Reports, 8(1), 14879.

Fokkens, H., Veselka, B., Bourgeois, Q., Olalde, I., \& Reich, D. (2017). Excavations of Late Neolithic arable, burial mounds and a number of well-preserved skeletons at Oostwoud-Tuithoorn: a reanalysis of old data. In H. Kamermans, \& C. Bakels (Eds.) Excerpta Archaeologica Leidensia II, (pp. 97-150). Leiden: Leiden University.

Frei, K. M., Bergerbrant, S., Sjögren, K.-G., Jørkov, M. L., Lynnerup, N., Harvig, L., et al. (2019). Mapping human mobility during the third and second millennia BA in present-day Denmark. PLoS One, 14(8), e0219850.

Fu, Q., Posth, C., Hajdinjak, M., Petr, M., Mallick, S., Fernandes, D., et al. (2016). The genetic history of Ice Age Europe. Nature, 534(7606), 200-205.

Furtwängler, A., Rohrlach, A. B., Lamnidis, T. C., Papac, L., Neumann, G. U., Siebke, I., et al. (2020). Ancient genomes reveal social and genetic structure of Late Neolithic Switzerland. Nature Communications, $11(1), 1915$.

Ghosh, S. (2016). Protein quality in the first thousand days of life. Food and Nutrition Bulletin, 37, S14-S21.

González-Fortes, G., Jones, E. R., Lightfoot, E., Bonsall, C., Lazar, C., Grandal-d'Anglade, A., et al. (2017). Paleogenomic Evidence for Multi-generational Mixing between Neolithic Farmers and Mesolithic Hunter-Gatherers in the Lower Danube Basin. Current Biology, 27(12), 18011810.e10.

Harpak, A., \& Przeworski, M. (2020). The evolution of group differences in changing environments. Hijmans, R. J., \& van Etten, J. (2012). raster: Geographic analysis and modeling with raster data. $\mathrm{R}$ package version 2.0-12. URL http://CRAN.R-project.org/package=raster 
406

407

408

409

410

411

412

413

414

415

416

417

418

419

420

421

422

423

424

425

426

427

428

429

430

431

432

433

434 Manouvrier, L. (1892). Determination de la taille d'apres les grands os des membres. Rev Men de 435 l'Ecole d'Anthrop, (pp. 227-233).

436 Marciniak, S., \& Perry, G. H. (2017). Harnessing ancient genomes to study the history of human 437

Kitti, K. (2008). The Physical Anthropological Characterization of the Population Connected to the Baden Culture in Hungary. In M. Furholt, M. Szmyt, \& A. Zastawny (Eds.) The Baden Complex and the Outside World, (pp. 95-110). Bonn: SAO/SPES 4.

Kjellström, A. (2005). The Urban Farmer: Osteoarchaeological analysis of skeletons form Medieval Sigtuna interpreted in a socioeconomic perspective. Ph.D. thesis, Theses and Papers in Osteoarchaeology No. 2, Stockholm University.

Kjellström, A., Storå, J., Possnert, G., \& Linderholm, A. (2009). Dietary patterns and social structures in medieval Sigtuna, Sweden, as reflected in stable isotope values in human skeletal remains. Journal of Archaeological Science, 36(12), 2689-2699.

Köhler, K., Marcsik, A., Kondor, K., \& Hajdu, T. (2017). The results of the physical anthropological study of the skeletal remains from the Late Copper Age mass graves at the site of Abony, Turjányos-dúlő, Hungary. Tagungen des Landesmuseums für Vorgeschichte Halle, 16, 377-386.

Köpke, N., \& Baten, J. (2005). Biological standard of living in Europe during the last two millennia. European Review of Economic History, 9(1), 61-95.

Krzewińska, M., Kjellström, A., Günther, T., Hedenstierna-Jonson, C., Zachrisson, T., Omrak, A., et al. (2018). Genomic and Strontium Isotope Variation Reveal Immigration Patterns in a Viking Age Town. Current Biology, 28(17), 2730-2738.e10.

Lehuray, J. D., Schutkowski, H., \& Richards, M. P. (2006). La Téne dietary variation in Central Europe: a stable isotope study of human skeletal remains from Bohemia. In C. Knüsel, \& B. Gowland (Eds.) The social Archaeology of Funeral Remains, (p. 99-121). Oxford: Oxbow Books.

Lipson, M., Szécsényi-Nagy, A., Mallick, S., Pósa, A., Stégmár, B., Keerl, V., et al. (2017). Parallel palaeogenomic transects reveal complex genetic history of early European farmers. Nature, $551(7680), 368-372$.

Malmström, H., Günther, T., Svensson, E. M., Juras, A., Fraser, M., Munters, A. R., et al. (2019). The genomic ancestry of the Scandinavian Battle Axe Culture people and their relation to the broader Corded Ware horizon. Proceedings of the Royal Society B: Biological Sciences, 286(1912), 20191528.

adaptation. Nat Rev Genet, 18(11), 659-674. 
460 461

462

Margaryan, A., Lawson, D. J., Sikora, M., Racimo, F., Rasmussen, S., Moltke, I., et al. (2020). Population genomics of the Viking world. Nature, 585(7825), 390-396.

Martin, A. R., Kanai, M., Kamatani, Y., Okada, Y., Neale, B. M., \& Daly, M. J. (2019). Clinical use of current polygenic risk scores may exacerbate health disparities. Nature Genetics, 51(4), $584-591$.

Martiniano, R., Caffell, A., Holst, M., Hunter-Mann, K., Montgomery, J., Müldner, G., et al. (2016). Genomic signals of migration and continuity in Britain before the Anglo-Saxons. Nature Communications, 7(1), 10326.

Massy, K. (2018). Die Gräber der Frühbronzezeit im südlichen Bayern - Untersuchungen zu den Bestattungs- und Beigabensitten sowie gräberfeldimmamenten Strukturen. ImVerlag Michael Lassleben: Kallmünz/Opf.

Mathieson, I., Alpaslan-Roodenberg, S., Posth, C., Szécsényi-Nagy, A., Rohland, N., Mallick, S., et al. (2018). Kinship-based social inequality in Bronze Age Europe. Nature, 555(7695), 197-203.

Mathieson, I., Lazaridis, I., Rohland, N., Mallick, S., Patterson, N., Roodenberg, S. A., et al. (2015). Genome-wide patterns of selection in 230 ancient Eurasians. Nature, 528(7583), 499-503.

Mittnik, A., Massy, K., Knipper, C., Wittenborn, F., Friedrich, R., Pfrengle, S., et al. (2019). Kinship-based social inequality in Bronze Age Europe. Science, 366(6466), 731-734.

Mittnik, A., Wang, C.-C., Pfrengle, S., Zarina, G., Hallgren, F., Allmäe, R., et al. (2018). The genetic prehistory of the Baltic Sea region. Nature Communications, 9(1).

Mostafavi, H., Harpak, A., Agarwal, I., Conley, D., Pritchard, J. K., \& Przeworski, M. (2020). Variable prediction accuracy of polygenic scores within an ancestry group. Elife, 9. URL https://www.ncbi.nlm.nih.gov/pubmed/31999256

Müldner, G., Chenery, C., \& Eckardt, H. (2011). The 'Headless Romans': multi-isotope investigations of an unusual burial ground from Roman Britain. Journal of Archaeological Science, 38(2), 280-290.

Narasimhan, V. M., Patterson, N., Moorjani, P., Rohland, N., Bernardos, R., Mallick, S., et al. (2019). The formation of human populations in South and Central Asia. Science, $365(6457)$.

NCD Risk Factor Collaboration (2016). A century of trends in adult human height. Elife, 5. URL https://www.ncbi.nlm.nih.gov/pubmed/27458798

Neale Lab, T. (2018). UK Biobank GWAS Results. http://www.nealelab.is/uk-biobank. Accessed: 2020-04-20. 
471

490 491

492

493 494 495

496 497 498

499 500

O'Brien, D. M. (2015). Stable Isotope Ratios as Biomarkers of Diet for Health Research. Annu Rev Nutr, 35, 565-594.

Olalde, I., Brace, S., Allentoft, M. E., Armit, I., Kristiansen, K., Booth, T., et al. (2018). The Beaker phenomenon and the genomic transformation of northwest Europe. Nature, 555(7695), 190-196.

Olalde, I., Mallick, S., Patterson, N., Rohland, N., Villalba-Mouco, V., Silva, M., et al. (2019). The genomic history of the Iberian Peninsula over the past 8000 years. Science, 363(6432), 1230-1234.

Pardini, E. (1977). The Human Remains from Aligrama Settlement (Swat, Pakistan). East and West, $27(1 / 4), 207-226$.

Pearson, K. (1899). On the Reconstruction of Stature in Prehistoric Races. Mathematical contribution to the theory of evolution. Transactions of the Royal Society A, (pp. 169-244).

Price, T. D., Peets, J., Allmäe, R., Maldre, L., \& Oras, E. (2016). Isotopic provenancing of the Salme ship burials in Pre-Viking Age Estonia. Antiquity, 90 (352), 1022-1037.

Racimo, F., Sikora, M., Vander Linden, M., Schroeder, H., \& Lalueza-Fox, C. (2020). Beyond broad strokes: sociocultural insights from the study of ancient genomes. Nature Reviews Genetics, 21 (6), 355-366.

Rosenstock, E., Ebert, J., Martin, R. D., Hicketier, A., Walter, P., \& Groß, M. (2019). Human stature in the Near East and Europe ca. 10,000-1,000 BC: Its spatiotemporal development in the Bayesian errors-in-variables mode. Archaeological and Anthropological Sciences, 11, 5657-5690.

Ruff, C., \& Holt, B. (2018). The Balkans. In C. B. Ruff (Ed.) Skeletal variation and adaptation in Europeans: Upper Paleolithic to the twentieth century. Hoboken, NJ: John Wiley \& Sons.

Ruff, C. B. (Ed.) (2018). Skeletal variation and adaptation in Europeans: Upper Paleolithic to the twentieth century. Hoboken, NJ: John Wiley \& Sons. (data available at https://www.hopkinsmedicine.org/fae/CBR.html).

Ruff, C. B., Holt, B. M., Niskanen, M., Sladék, V., Berner, M., Garofalo, E., et al. (2012). Stature and body mass estimation from skeletal remains in the European Holocene. American Journal of Physical Anthropology, 148(4), 601-617.

Saag, L., Vasilyev, S. V., Varul, L., Kosorukova, N. V., Gerasimov, D. V., Oshibkina, S. V., et al. (2020). Genetic ancestry changes in Stone to Bronze Age transition in the East European plain. bioRxiv.

Scheibner, A. (2016). Prähistorische Ernährung in Vorderasien und Europa. Eine kulturgeschichtliche Synthese auf der Basis ausgewählter Quellen. Schriften zum Lebensstandard in der Vorgeschichte 1. Leidorf: Rahden: Berliner Archäologische Forschungen. 
502

503

504

505

506

507

508

509

510

511 512

513 514

515

516

517

518

519

520

521

522

523

524

525

526

527 528

529 Torkamani, A., Wineinger, N. E., \& Topol, E. J. (2018). The personal and clinical utility of polygenic 530

531 Trotter, M., \& Gleser, G. C. (1952). Estimation of stature from long bones of American Whites 532

Schiffels, S., Haak, W., Paajanen, P., Llamas, B., Popescu, E., Loe, L., et al. (2016). Iron Age and Anglo-Saxon genomes from East England reveal British migration history. Nature Communications, 7(1), 2041-1723.

Schroeder, H., Margaryan, A., Szmyt, M., Theulot, B., Włodarczak, P., Rasmussen, S., et al. (2019). Unraveling ancestry, kinship, and violence in a Late Neolithic mass grave. Proceedings of the National Academy of Sciences, 116(22), 10705-10710.

Sikora, M., Seguin-Orlando, A., Sousa, V. C., Albrechtsen, A., Korneliussen, T., Ko, A., et al. (2017). Ancient genomes show social and reproductive behavior of early Upper Paleolithic foragers. Science, 358(6363), 659-662.

Sjøvold, T. (1990). Estimation of stature from long bones utilizing the line of organic correlation. Human Evolution, 5(5), 431-447.

Skoglund, P., \& Mathieson, I. (2018). Ancient Genomics of Modern Humans: The First Decade. Annu Rev Genomics Hum Genet, 19, 381-404.

Sládek, V., Macháček, J., Ruff, C. B., Schuplerova, E., Prichystalova, R., \& Hora, M. (2015). Population-specific stature estimation from long bones in the early medieval Pohansko (Czech Republic). American Journal of Physical Anthroplogy, 158(2), 312-324.

Sohail, M., Maier, R. M., Ganna, A., Bloemendal, A., Martin, A. R., Turchin, M. C., et al. (2019). Polygenic adaptation on height is overestimated due to uncorrected stratification in genome-wide association studies. eLife, 8, e39702.

Stockhammer, P. W., Massy, K., Knipper, C., Friedrich, R., Kromer, B., Lindauer, S., et al. (2015). Rewriting the central European Early Bronze Age chronology: Evidence from large-scale radiocarbon dating. PLoS One, 10(10), e0139705.

Szczepanek, A. (2013). Analiza antropologiczna szkieletów. In M. M. Przybyła, A. Szczepanek, \& P. Włodarczak (Eds.) Koszyce, stanowisko 3 Przemoc i rytuał u schytku neolitu, (pp. 65-92). Kraków-Pękowice: Profil-Archaeo Publishing House and Archaeological Studio.

Tebelškis, P., \& Jankauskas, R. (2002). The late Neolithic grave at Gyvakarai in Lithuania in the context of archaeological and anthropological knowledge. Archaeologia Baltica, 6, 8-20.

risk scores. Nat Rev Genet, 19(9), 581-590. and Negroes. American Journal of Physical Anthropology, 10(4), 463-514. 
533 Vilhjalmsson, B. J., Yang, J., Finucane, H. K., Gusev, A., Lindstrom, S., Ripke, S., et al. (2015).

534 Modeling Linkage Disequilibrium Increases Accuracy of Polygenic Risk Scores. Am J Hum Genet, $\mathbf{5 3 5} 97(4), 576-92$.

536 URL https://www.ncbi.nlm.nih.gov/pubmed/26430803

537 Visscher, P. M., Wray, N. R., Zhang, Q., Sklar, P., McCarthy, M. I., Brown, M. A., et al. (2017).

53810 Years of GWAS Discovery: Biology, Function, and Translation. American Journal of Human

539 Genetics, 101(1), 5-22.

540 Wallace, J. R. (2012). Imap: Interactive Mapping. R package version 1.32.

$\mathbf{5 4 1}$ URL https://cran.r-project.org/package=Imap

542 Waterman, A. J., Tykot, R. H., \& Silva, A. M. (2016). Stable Isotope Analysis of Diet-based Social 543 Differentiation at Late Prehistoric Collective Burials in South-Western Portugal. Archaeometry, $\mathbf{5 4 4} 58(1), 131-151$.

545 Weber, A. W., Schulting, R. J., Ramsey, C. B., \& Bazaliiskii, V. I. (2016). Biogeochemical data 546 from the Shamankaa II Early Neolithic cemetery on southwest Baikal: Chronological and dietary 547 patterns. Quaternary International, 405, 233-254.

548 Weber, A. W., White, D., Bazaliiskii, V. I., Goriunova, O. I., Savel'ev, N. A., \& Anne Katzen549 berg, M. (2011). Hunter-gatherer foraging ranges, migrations, and travel in the middle Holocene 550 Baikal region of Siberia: Insights from carbon and nitrogen stable isotope signatures. Journal of $551 \quad$ Anthropological Archaeology, 30(4), 523-548.

552 Yengo, L., Sidorenko, J., Kemper, K. E., Zheng, Z., Wood, A. R., Weedon, M. N., et al. (2018). 553 Meta-analysis of genome-wide association studies for height and body mass index in $~ 700000$ $\mathbf{5 5 4}$ individuals of European ancestry. Hum Mol Genet, 27(20), 3641-3649. 